\title{
Process Improvements and Characterization of Ultrasonic Additive Manufactured Structures
}

\author{
P.J. Wolcott, A. Hehr, C. Pawlowski, M.J. Dapino ${ }^{1}$ \\ Department of Mechanical and Aerospace Engineering, The Ohio State University \\ 201 W. 19th Ave, Columbus, OH, USA
}

\begin{abstract}
Ultrasonic additive manufacturing (UAM) is a solid state joining technology that produces metal parts and components at low temperatures by utilizing principles of ultrasonic metal welding. The process can produce solid and gapless structures, however under certain processing conditions voids and poor mechanical properties may occur. Builds wider than the foil width require stacking of foils next to and on top of one another, leading to the potential for voids, while also requiring periodic machining to maintain flatness. This study proposes a methodology to improve the bonding and mechanical properties of Al 6061 UAM builds. Specifically, the stacking sequence of foil layers, the effects of surface roughness during welding and following machining, and post-process heat treatments are examined. An optimized stacking sequence for foils has been identified via mechanical strength testing, whereby tape to tape overlap should be greater than 0.0025 in. $(0.0635 \mathrm{~mm})$ using a randomized layer stacking sequence. Sonotrodes with a 14 $\mu \mathrm{m} \mathrm{R}_{a}$ surface roughness are shown to provide improved bond quality compared to sonotrodes with $7 \mu \mathrm{m}$ roughness. Welding onto surfaces roughened with the sonotrode after flattening passes has also shown to improve bond strength. Post-process heat treatments increase the bond strength over as-built conditions, providing strengths close to $90 \%$ of bulk material.
\end{abstract}

Keywords: Ultrasonic additive manufacturing, ultrasonic consolidation, surface roughness, heat treatment, aluminum, mechanical testing

${ }^{1}$ Corresponding Author: e-mail: dapino.1@ osu.edu, phone: 614-688-3689 


\section{Introduction}

Ultrasonic additive manufacturing (UAM) is a solid state joining technology that uses ultrasonic vibrations developed by piezoelectric transducers to join thin metal foils. The ultrasonic vibrations operate around $20 \mathrm{kHz}$, generating a scrubbing action at the mating interface of a prospective joint through contact with a horn or sonotrode, as described by White (2003) [1] This scrubbing action combined with a normal force creates local plastic deformation, collapses asperities, and displaces oxides and contaminants, which according to Graff (2005), leads to nascent metal surfaces and bonding [2]. The process is conducted in a continuous rolling action where successive foils are joined on top of or next to a previously bonded layer.

UAM systems are often integrated into a CNC framework used for subtractive milling operations, in addition to the additive stage associated with welding. Using the additive and subtractive stages in tandem, UAM can be used to create unique geometries or integrated channels for thermal management devices or other such components, as exhibited by Norfolk and Johnson (2015) producing cooling devices [3]. UAM is a low temperature process, with operating temperatures below $50 \%$ of the melting temperature of aluminum, as shown by Sriraman et al. (2010) [4]. Because it is low temperature, UAM is a proven method of creating composite structures with embedded components such as smart materials and electronics which would otherwise be damaged in high temperature thermal joining processes. Examples include embedding shape memory alloy (SMA) fibers in aluminum by Kong et al. (2004) [5], creation of active composites with shape memory alloy fibers by Hahnlen and Dapino (2014) [6], embedment of fiber optics by Kong and Soar (2005) [7], and embedding temperature sensitive sensors into metallic structures by Siggard (2007) [8]. Additionally, the low temperature nature of the process allows for joining of dissimilar materials without generation of detrimental intermetallics. Examples include Al-Ti combinations exhibited by Hopkins et al. (2010) [9], Al-Cu by Truog (2012) [10], Al-steel, and many other combinations by Obielodan et al. (2010) [11].

Process parameters commonly controlled during welding operations include normal force, oscillation amplitude, and rolling speed. These weld parameters can have a significant influence on bond quality, with an optimal value for each parameter varying depending on the materials being joined. For example, Hopkins et al. (2010) [9] identified that normal force and weld speed are significant for Al-Ti combinations while studies by Wolcott et al. (2014) [12] and Hopkins et al. (2012) [13] indicate that amplitude and weld speed are significant for Al-Al combinations. 
Recent advances in the available ultrasonic power for welding from $1 \mathrm{~kW}$ to $9 \mathrm{~kW}$ demonstrated by Graff et al. (2011) [14], have increased the capacity for normal force to be applied during welding, while maintaining a given oscillation amplitude. This power increase enables joining more material combinations and increased the potential designs for welded joints. Moreover, Fujii et al. (2011) have shown that the increase in available power has led to a strong decrease in voids within UAM builds [15]. Typical welds with Al 6061 using the $9 \mathrm{~kW}$ process require 2

\section{$\mathrm{kW}$ of ultrasonic power for strong joints.}

Current UAM equipment can create parts on the order of several feet on each side, limited only by the currently available table dimensions. In taking advantage of the full dimensions of this build envelope, detrimental effects to weld quality due to structural compliance and resonance phenomena must be considered. Robinson et al. (2006) have shown that the increased compliance of free standing structures as build height increases leads to a lack of surface deformation required for bonding [16]. Hehr et al. demonstrated that less mechanical power is applied when compliance increases and propose an approach to compensate for this effect [17]. Gibert et al. (2010) have shown that at specific height to width ratios, structural resonances can become excited leading to a lack of relative motion of work pieces and poor bonding [18].

Wider builds can remedy these issues, however they require abutting tapes next to one another, which in turn creates a source for void formation, as exhibited by Obielodan et al. (2010) [19]. Overlapping of tapes can minimize or prevent void formation at the abutments, but the build surface becomes less flat and uniform due to accumulation of material at the seam locations. An example of a UAM build exhibiting poor flatness and accumulation of material at the seams due to tape overlap is shown in Figure 1. Periodic flattening passes conducted regularly throughout the build using the $\mathrm{CNC}$ stage in state of the art UAM systems can remove this material. However, inhomogeneities are created within the build because some layers are welded onto surfaces textured by the sonotrode, while others are welded onto a smoothly machined surface. Consequently it is necessary to understand the effect welding onto smooth and textured surfaces has on bond quality. 


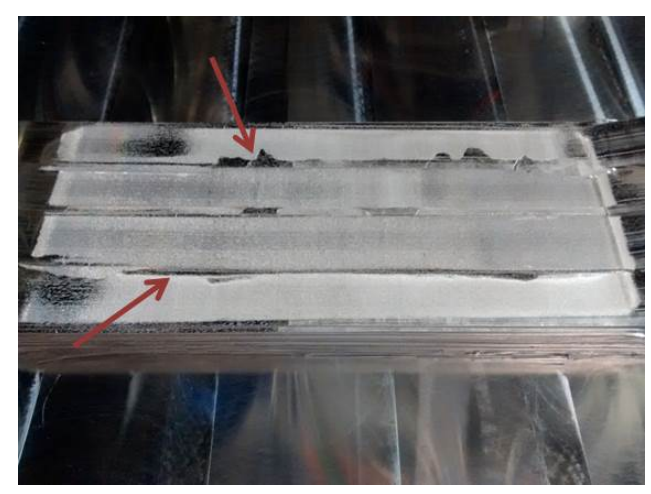

Figure 1: Block build showing thickness variations at seam locations with arrows indicating areas of material accumulation.

The purpose of this paper is to outline investigations performed to improve the UAM process for aluminum 6061 material. Improvements addressed in this paper include the interrelated issues of tape overlap and roughness, as well as investigation of post-process heat treatments which have been shown to improve material properties. Section 2 describes the relevant research problems in detail, with previous work and potential methods of addressing them. Section 3 describes a study on the optimal overlap and stacking sequence of foils. In section 4 the effect of surface roughness on the UAM process is investigated, examining the roughness of sonotrodes for welding as well as the effect of welding onto smooth or roughened surfaces. Section 5 describes a study on the effect heat treatment has on UAM Al 6061 tensile properties through testing as-built, annealed, and samples aged to the T6 condition. All work performed in this study used a $9 \mathrm{~kW}$ Fabrisonic SonicLayer 4000 UAM system [20]. The system is fully automated and includes CNC milling capabilities.

\section{Background}

To minimize void formation at tape abutment points and improve bond quality, an overlap can be utilized when welding tapes next to one another. A schematic of this overlap concept is shown in Figure 2, where tapes are laid on top of one another at the abutment and the potential void is filled in via plastic deformation. Tape stacking or stagger is shown in Figure 2 as the variable distance between abutment joints of successive layers. If the tape joints are all aligned at the same location in the UAM build, localized void concentration and the risk of cracking 
along this seam increases. Utilizing a brick-like stagger pattern between successive layers can minimize crack formation and void concentration within the build. Previous work conducted by Obielodan et al. (2010), studied the effect of tape overlap and stagger of successive Al 3003 foils on bond quality for $1 \mathrm{~kW}$ UAM [19]. A similar study needs to be performed on $9 \mathrm{~kW}$ UAM, investigating whether differences in material build up occurs at seam locations and whether a new overlap and stacking scheme is required for $9 \mathrm{~kW}$ UAM.

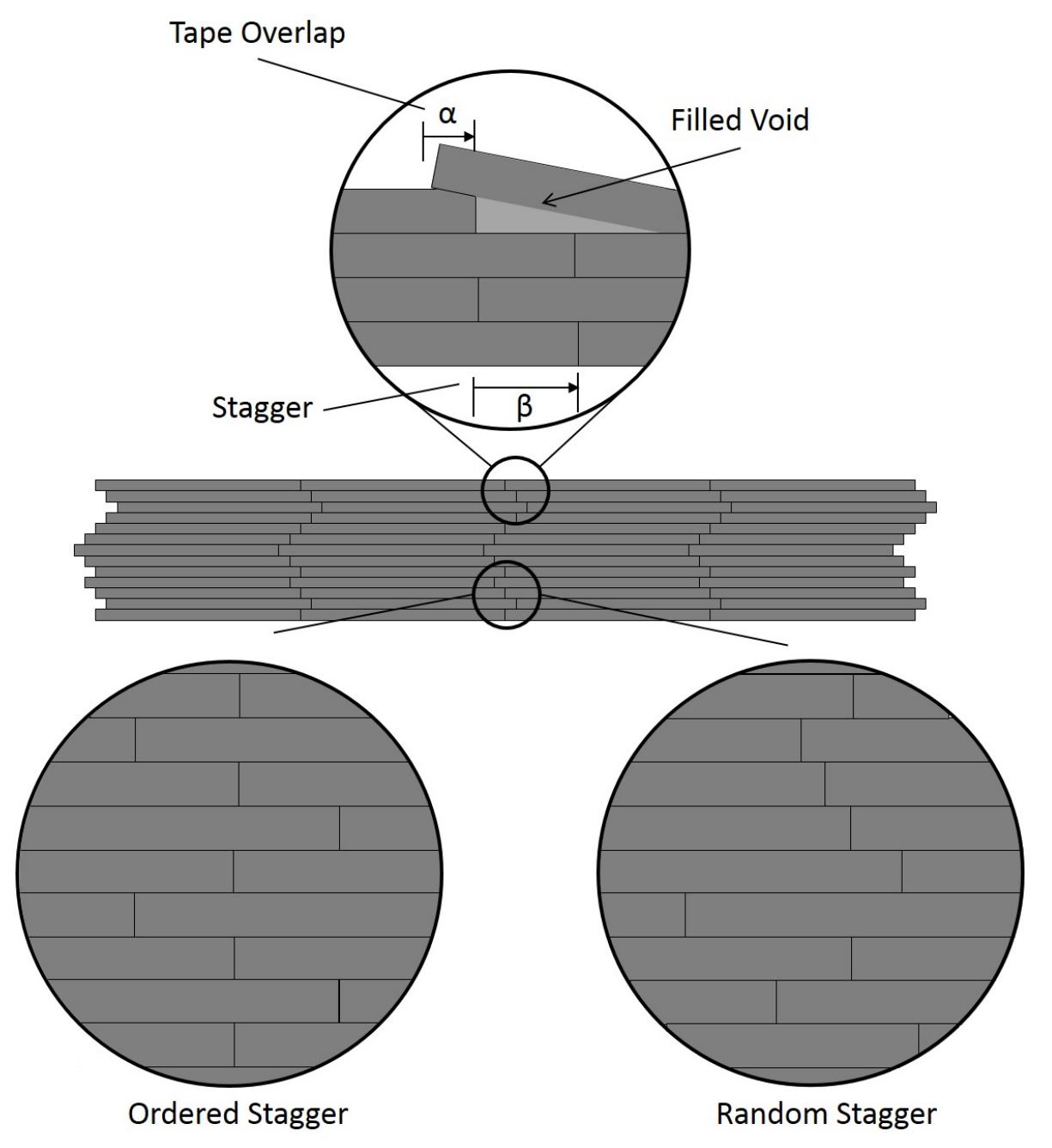

Figure 2: Tape overlap and stagger, i.e., stacking sequence, with potential void filled in via plastic deformation of the tape. 
Surface texture or roughness has been shown to play an important role in UAM. Li and Soar (2009) showed that a rougher sonotrode surface in $1 \mathrm{~kW}$ UAM produced improved interlaminar bonds due to improved energy transfer (2009) [21]. However, a rougher sonotrode surface created more voids at the weld interface due to insufficient plastic deformation of the larger surface asperities. Related work by Friel et al. (2010) in $1 \mathrm{~kW}$ UAM indicated that an optimal roughness for joining may exist to create strong bonds while simultaneously minimizing voids [22]. Work by Ram et al. (2006) in $1 \mathrm{~kW}$ UAM suggests that a nearly void-less interface can be achieved when welding on smooth surfaces [23]. However, Hopkins et al. (2012) showed that a void-less interface is not sufficient for achieving optimal mechanical strength [13]. Truog (2012) showed that in $9 \mathrm{~kW}$ UAM, a rougher surface improved bonding [10]; yet an optimal surface roughness was not identified, and the bond enhancement mechanism was not fully understood.

Post-process or post-weld heat treatments have shown to improve mechanical properties by altering the bulk and interface microstructure. Work by Truog (2012) indicates that post-process heat treatments can improve mechanical properties for $\mathrm{Al}-\mathrm{Cu}$ joints without generation of harmful intermetallics [10]. Sojiphan et al. (2012) [24] have shown that heat treatments induce recrystallization and grain growth near bond interfaces in Al 3003, and Zhang (2011) [25] has shown that heat treatments can significantly improve mechanical properties for Al 3003 joints. In work by the authors (2014), annealing was performed on Al 6061 samples built using $9 \mathrm{~kW}$ UAM with resulting strength increases compared to as-built samples [12]. Because Al 6061 is an age-hardenable material, heat treatments can be used to maximize mechanical strength.

\section{Overlap and Stacking Sequence}

\subsection{Experimental}

In this study, UAM builds were constructed to investigate the effect of tape to tape overlap and stacking sequence on strength. Al 6061-H18 foils, 0.006 in. (0.1524 mm) thick, 1 in. (25.4 $\mathrm{mm}$ ) wide were used; built onto an Al 6061-T6 baseplate. Al 6061-H18 is an age hardenable material which was welded in the annealed heat treatment and H18 cold-worked condition. The weld parameters used for the builds follow previously optimized values for Al 6061 by Wolcott et al. (2014) [12], as presented in Table 1. The normal force and weld speed are specified inputs in the machine software. The amplitude value is specified as a percentage of voltage applied to the piezoelectric transducers to achieve a given vibration amplitude. The vibration amplitude 
is calibrated prior to welding operations by exciting the welder under no load (vibrating in air) and measuring the vibration magnitude with a laser vibrometer. All builds were manufactured at room temperature using a $7 \mu \mathrm{m} \mathrm{R}_{a}$ roughness sonotrode.

Table 1: Weld settings for UAM builds.

\begin{tabular}{|c|c|}
\hline Weld Parameter & Level \\
\hline Normal Force & $5000 \mathrm{~N}$ \\
\hline Amplitude & $32.8 \mu \mathrm{m}$ \\
\hline Weld Speed & $200 \mathrm{in} / \mathrm{min}(84.6 \mathrm{~mm} / \mathrm{s})$ \\
\hline
\end{tabular}

Two build plates were used to investigate each of the effects with each of the sample sets summarized in Table 2. In plate 1, the stacking remained constant while the tape to tape overlap ( $\alpha$ in Figure 2) was varied from 0.0015 in. $(0.038 \mathrm{~mm})$ to 0.0045 in. $(0.1143 \mathrm{~mm})$. In the SonicLayer system, this is achieved by using a constant $1 \mathrm{in} .(25.4 \mathrm{~mm})$ wide tape and setting the tape width to varying levels. The specified tape overlaps were selected at levels which provide overlap while minimizing flash, or excess material, at the abutment points. The ordered stacking sequence followed a $0,1,0,-1 \ldots$ sequence as shown in Figure 2. The amount of stagger is described by $\beta$ as shown in Figure 2. In plate 2, the tape overlap was held constant while the stacking sequence was varied. Samples A and B were built using similar $0,1,0,-1,0$ ordered stacking sequences with varying amounts of stagger. Build $\mathrm{C}$ used random stacking with a maximum stagger value of $\beta=0.3$ in. (7.62 mm). Build D used ordered stacking with $\mathbf{5 0 \%}$ stagger from tape to tape. Stacking sequences were selected such that both randomized and ordered sequences were investigated and the entire design space of stagger values was covered.

Tensile samples were sectioned from the blocks using the CNC stage on the machine following ASTM subsize tensile sample dimensions [26] such that testing occurs across the various tape interfaces, transverse to the welding direction. Tensile tests were performed on a $22 \mathrm{kip}$ $(98.7 \mathrm{kN})$ Interlaken 3300 test frame, using a displacement rate of $0.05 \mathrm{in} / \mathrm{min}(1.27 \mathrm{~mm} / \mathrm{min})$ while recording the load to failure.

\subsection{Results and Discussion}

Ultimate tensile strength (UTS) results are summarized in Table 3. From the results of test data from Plate 1, there is a clear delineation between the first two samples (A and B) and the 
Table 2: Overlap and stacking sequence prescribed for each sample set.

\begin{tabular}{|c|c|c|}
\hline Sample Set & Overlap $(\alpha$ in mm $)$ & Stacking Sequence $(\beta$ in mm $)$ \\
\hline 1A & 0.0381 & Ordered with $\beta=3.81$ \\
\hline 1B & 0.0635 & Ordered with $\beta=3.81$ \\
\hline 1C & 0.0889 & Ordered with $\beta=3.81$ \\
\hline 1D & 0.1143 & Ordered with $\beta=3.81$ \\
\hline 2A & 0.0762 & Ordered with $\beta=2.54$ \\
\hline 2B & 0.0762 & Ordered with $\beta=3.81$ \\
\hline 2C & 0.0762 & Random with $\beta=7.62$ at maximum \\
\hline 2D & 0.0762 & Ordered with $\beta=12.6238(50 \%$ stagger $)$ \\
\hline
\end{tabular}

last two samples (C and D), with samples $C$ and D producing strengths of approximately 210 MPa on average vs. $128 \mathrm{MPa}$ for samples A and B. Results of test data from Plate 2 indicate that build $\mathrm{C}$ resulted in the highest tensile strength, 222.5 MPa on average.

\begin{tabular}{|c|c|c|c|c|c|c|c|c|}
\multicolumn{8}{c|}{ Table 3: Tensile test results for overlap and stacking study. } \\
\hline UTS (MPa) & $1 \mathrm{~A}$ & $1 \mathrm{~B}$ & $1 \mathrm{C}$ & $1 \mathrm{D}$ & 2A & $2 \mathrm{~B}$ & $2 \mathrm{C}$ & $2 \mathrm{D}$ \\
\hline 1 & 133.1 & 121.7 & 202.3 & 227.1 & 225.5 & 185.1 & 221.7 & 184.2 \\
\hline 2 & 117.7 & 129.8 & 214.7 & 178.8 & 177.5 & 196.3 & 223.9 & 163.7 \\
\hline 3 & 124.0 & 144.2 & 211.4 & 228.2 & 185.1 & 167.7 & 222.0 & 153.6 \\
\hline Mean & 124.9 & 131.9 & 209.5 & 211.4 & 196.0 & 183.0 & 222.5 & 167.2 \\
\hline St Dev & 7.7 & 11.4 & 6.4 & 28.2 & 25.8 & 14.4 & 1.2 & 15.6 \\
\hline
\end{tabular}

Optical microscopy shows that voids are found in increasing numbers for the sample sets with lower strengths. Figure 3(a) shows an image of sample 1B where voids are present, while Figure 3(b) shows sample 1D with no voids present. The stacking type voids were found in both samples $1 \mathrm{~A}$ and 1B. The propensity for void formation in sample sets with low overlap is expected to significantly decrease the mechanical strength of the builds. While significant voids were not found in samples on plate 2, it is expected that weak points may exist at the areas of tape to tape layup that cannot be seen using optical microscopy leading to decreased strength. Previous work by Hopkins et al. (2012) has also shown that void content alone is not a sufficient metric for characterizing bond strength [13], supporting this hypothesis. Sample 2C exhibited 
the highest strengths and consistency in this study; likely due to a hindrance of crack propagation through adjoining weak points in the material by creating a tortuous crack path.

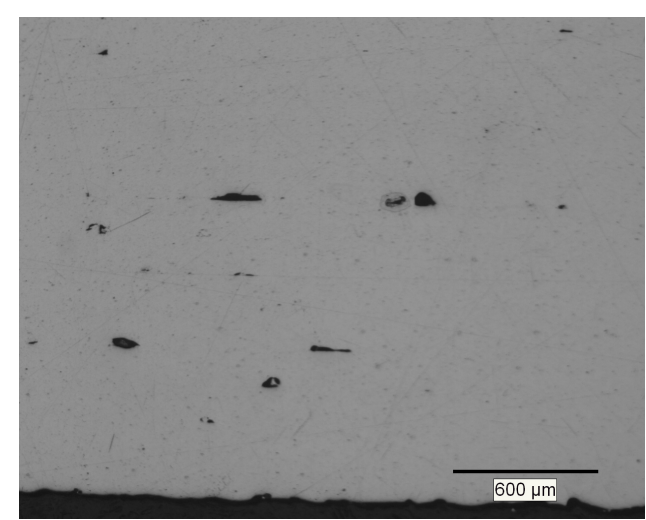

(a)

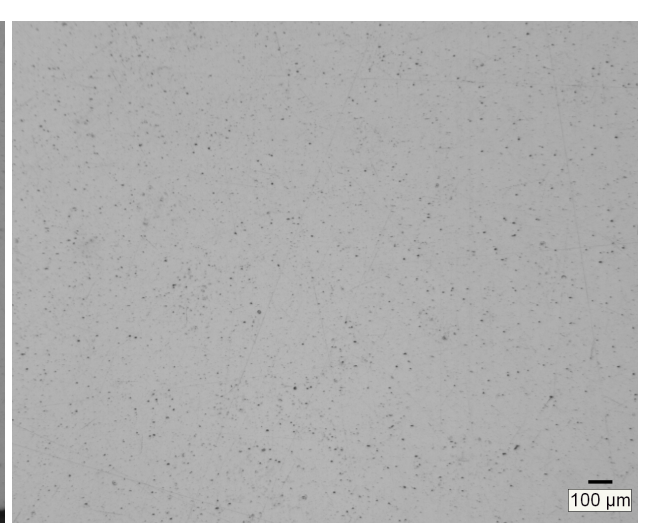

(b)

Figure 3: (a) Cross section of UAM build showing voids in Sample 1B and (b) cross section of sample 1D with no voids.

Based on these results it is recommended that for UAM block builds, a tape to tape overlap of at least $0.0025 \mathrm{in} .(0.0635 \mathrm{~mm})$ be used and that the stacking sequence follow a random stacking with maximum stagger of 0.3 in. $(7.62 \mathrm{~mm})$. Tape to tape overlap results are consistent with those found by Obielodan et al. (2010) in $1 \mathrm{~kW}$ UAM [19], which recommend use of overlaps of at least $0.00275 \mathrm{in}$. (0.07 mm). Stacking sequences recommended by Obielodan et al. (2010) use a 50\% stagger, however only two stacking methods were investigated, while the study presented here investigated four separate stacking sequences. Of note, these recommendations are based on the testing performed here. These parameters are valid only within the optimized parameter set used here, further a globally optimal value may be achieved through further optimization. The recommended stacking sequence proposed is based on the findings from sample $2 \mathrm{C}$, indicating that randomized stacking should be used. However, the magnitude of the proposed stagger may not scale in taller builds where tape flash at the build edge creates areas of poor support leading to inconsistent welds at the build edge. This effect can propagate inward as a build progresses higher, making further welds near the edges difficult. In these instances, a random stacking pattern with smaller stagger should be used. 


\section{Effect of Surface Roughness}

\subsection{Experimental}

\subsubsection{Weld Layer Texture}

To study the texture of flattening passes and their effect on UAM strength, builds were conducted with welds onto smooth, freshly machined surfaces and welds onto roughened surfaces. Flattening passes were performed using a carbide insert shell mill within the CNC stage of the UAM machine creating a smooth surface. Roughened surface samples were built onto surfaces which were textured by vibrating the sonotrode at a low amplitude, similar to welding operations. The roughness of the machined surface is $0.12 \mu \mathrm{m} \mathrm{R}$ and the roughened surface is $5.7 \mu \mathrm{m}$ $\mathrm{R}_{a}$, measured with a Mitutoyo mechanical probe profilometer. The builds contained flattening passes every third layer, starting at the fifth layer. Each build consisted of 20 total layers such that five flattened surfaces were introduced into each build. All builds were constructed onto a 0.5 in $(12.7 \mathrm{~mm})$ thick Al 6061-T6 baseplate with Al 6061-H18 foils 1 in. (25.4 mm) wide and 0.006 in. $(0.1524 \mathrm{~mm})$ thick. Weld parameters follow those listed in Table 1.

Sample strength was measured via push-pin testing to compare delamination strength and resistance. The push-pin test is a relatively quick, comparative test that has proven useful in previous UAM studies. Push-pin testing was developed by Zhang et al. (2011) [27] and uses a pin to push on welded layers through a blind hole within the sample, causing delamination. Work by Truog (2012) has used push-pin testing for examining the bond strength of Al-Cu joints produced using the UAM process [10]. Wolcott et al. (2014) used this test for comparing bond strength of UAM Al structures prepared using varying process parameters [12]. The measurements in this study were conducted using a Gleeble 3800 thermomechanical frame at room temperature while measuring both push-out force and machine displacement. Mechanical work or energy (force-displacement) was then calculated from these results and used in evaluation of UAM bond strength. More information on test setup and methodology can be found in literature by Zhang [27] and Wolcott [12].

\subsubsection{Sonotrode Roughness}

A second study involving surface roughness was performed to determine the effect of sonotrode roughness on weld quality. In this study, samples were fabricated using sonotrodes of $7 \mu \mathrm{m}$ and 
$14 \mu \mathrm{m} \mathrm{R}_{a}$ roughness, respectively. Both of these sonotrodes were textured with electron discharge machining to create the desired surface profile. Two 12 in. $(30.5 \mathrm{~cm})$ long, 1 in. (25.4 $\mathrm{mm}$ ) wide build strips 20 layers tall were constructed using each sonotrode, each with identical weld parameters as those listed in Table 1. The strips were built onto a 0.5 in. thick Al 6061T6 baseplate, yielding eight total push-pin samples. One of the $7 \mu \mathrm{m}$ roughness samples was damaged during machining, therefore 15 total samples were tested in this study.

The UAM weld parameters of speed, normal force, and temperature are not a function of welder dynamics during welding. On the other hand, weld displacement is a function of welder dynamics due to small amounts of compliance in the sonotrode during welding. To ensure that weld motion was the same for each sonotrode, a Polytec laser vibrometer was utilized to measure velocity during welding operations. Velocity measurements were made at the second layer of each stack and are shown in Figure 4. As is shown, peak weld velocity is similar amongst the stacks. Black dashed lines show the approximate bounds of the measurements for comparison purposes.

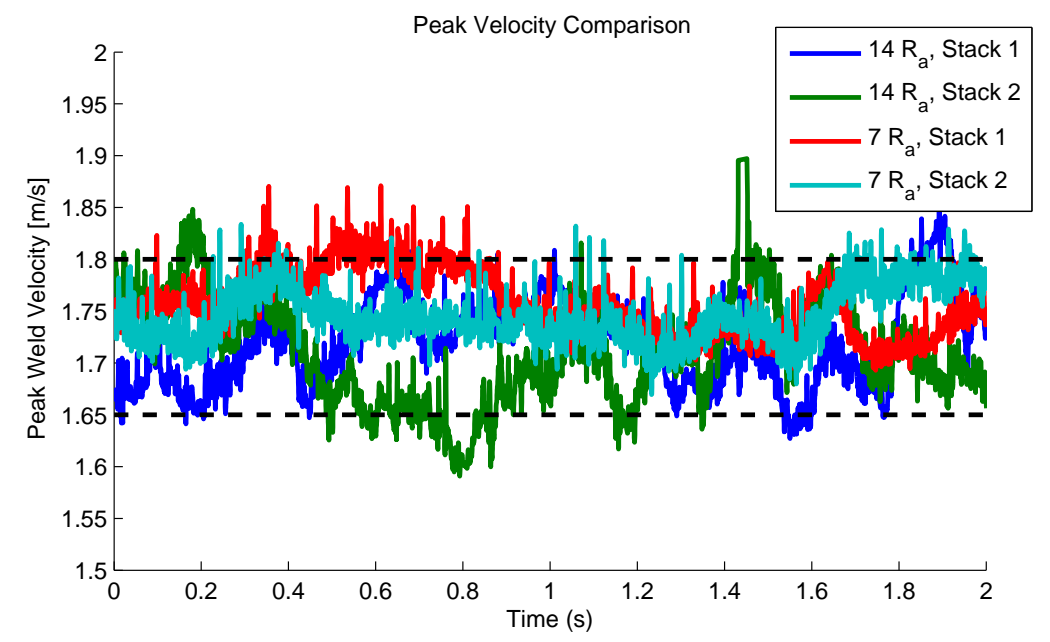

Figure 4: Peak weld amplitude measurement under load during welding. Measurements were taken at the second layer of each stack. Similar weld amplitude levels were utilized to weld all the stacks. 


\subsection{Results and Discussion}

\subsubsection{Weld Layer Texture}

Push-pin test results are provided in Table 4. Of note, one textured sample was damaged during test setup and was not tested. The mean peak force for the textured samples $(4.42 \mathrm{kN})$ is similar to the non-textured samples $(4.45 \mathrm{kN})$. However the mechanical work, or energy, of the textured samples shows a difference. The non-textured samples exhibited an average push-out energy of $5.51 \mathrm{kN}$-mm compared to $4.75 \mathrm{kN}$-mm for the non-textured samples. To evaluate this energy difference statistically, a t-test was conducted using JMP statistical software assuming unequal variance between the two samples to determine the p-value, or probability of obtaining a test at least as extreme as the one observed. The lower the p-value, the stronger the evidence against the null hypothesis. When $\mathrm{p}<\alpha$, where $\alpha$ is the type I error probability and $\alpha=0.05$ in this case, the null hypothesis is rejected indicating a statistically significant effect or trend. A p-value of 0.21 was calculated for the data, which is greater than 0.05 , suggesting that texturing does not have a statistically significant effect on weld strength.

\begin{tabular}{|c|c|c|c|c|}
\hline \multicolumn{2}{|c}{ Table 4: Push-pin data for textured and nontextured builds. } \\
\hline Sample & \multicolumn{2}{|c|}{ Textured } & \multicolumn{2}{c|}{ Non-Textured } \\
$(\mathrm{kN})$ & $\begin{array}{c}\text { Peak Force } \\
\left(\mathrm{kN}^{*} \mathrm{~mm}\right)\end{array}$ & $\begin{array}{c}\text { Peak Force } \\
(\mathrm{kN})\end{array}$ & $\begin{array}{c}\text { Energy } \\
\left(\mathrm{kN}^{*} \mathrm{~mm}\right)\end{array}$ \\
\hline 1 & 4.66 & 5.32 & 4.28 & 3.82 \\
\hline 2 & 4.18 & 5.47 & 4.66 & 5.50 \\
\hline 3 & 4.42 & 5.74 & 4.51 & 5.58 \\
\hline 4 & - & - & 4.35 & 4.11 \\
\hline Mean & 4.42 & 5.51 & 4.45 & 4.75 \\
\hline St Dev & 0.20 & 0.17 & 0.15 & 0.80 \\
\hline
\end{tabular}

In addition to strength improvements, textured samples produce more consistent weld properties than non-textured samples. As shown in Table 4, the push-out energy standard deviation for the textured samples is 0.17 whereas the non-textured sample standard deviation is 0.80 . To evaluate the variances statistically, the equivalence of the variance was tested using unequal variance t-tests with $\alpha=0.05$. The null hypothesis of these tests is that the two samples have 
equal variances. Consequently, a p-value below 0.05 indicates that the two samples are not statistically equal. It was found that the variance difference was significant at the 0.05 level for the OBrien, Brown-Forsythe, and Levene unequal variance tests. The Bartlett test calculated a $\mathrm{p}$-value of 0.09. Due to 3 out of the 4 unequal variance tests showing statistical significance, texturing should be used after surface flattening when applicable to improve strength and weld consistency.

The improvements in weld properties due to surface texturing are believed to originate at the weld interface. Better bonds have been shown to have more recrystallization in the bond zone. It is hypothesized that the increased surface roughness after texturing enhances the driving force for dynamic recrystallization through asperity deformation during welding leading to increases in plastic deformation, oxide dispersal, and mixing. In combination, these factors increase the potential for recrystallization and grain growth across the bond interface leading to improved metallurgical bonding as shown by Dehoff and Babu (2010) [28]. To further investigate this phenomenon, in depth characterization of the grain structure at the interface will be required.

The retexturing process following machining increases build time by approximately $5 \%$. However based on these findings, the increase in build time is offset by the improvements in weld quality. It is therefore a necessary step to producing the highest strength bonds.

\subsubsection{Sonotrode Roughness}

Push-pin results comparing the two sonotrode roughnesses are shown in Figure 5 and Table 5. Samples were tested in a randomized order to eliminate any bias. As seen in the figure and table, the $14 \mu \mathrm{m}$ samples exhibit a larger peak force and a similar push-out energy compared to the $7 \mu \mathrm{m}$ samples. To evaluate the outputs of peak force and push-out energy statistically, t-tests with the assumption of unequal variance were conducted, with results shown in Table 6. These results show that the peak force between the two samples is statistically different at the 0.05 level. Although the push-out energy does not show statistical significance, the results show that the 14 $\mu \mathrm{m}$ sonotrode does not degrade weld strength. 

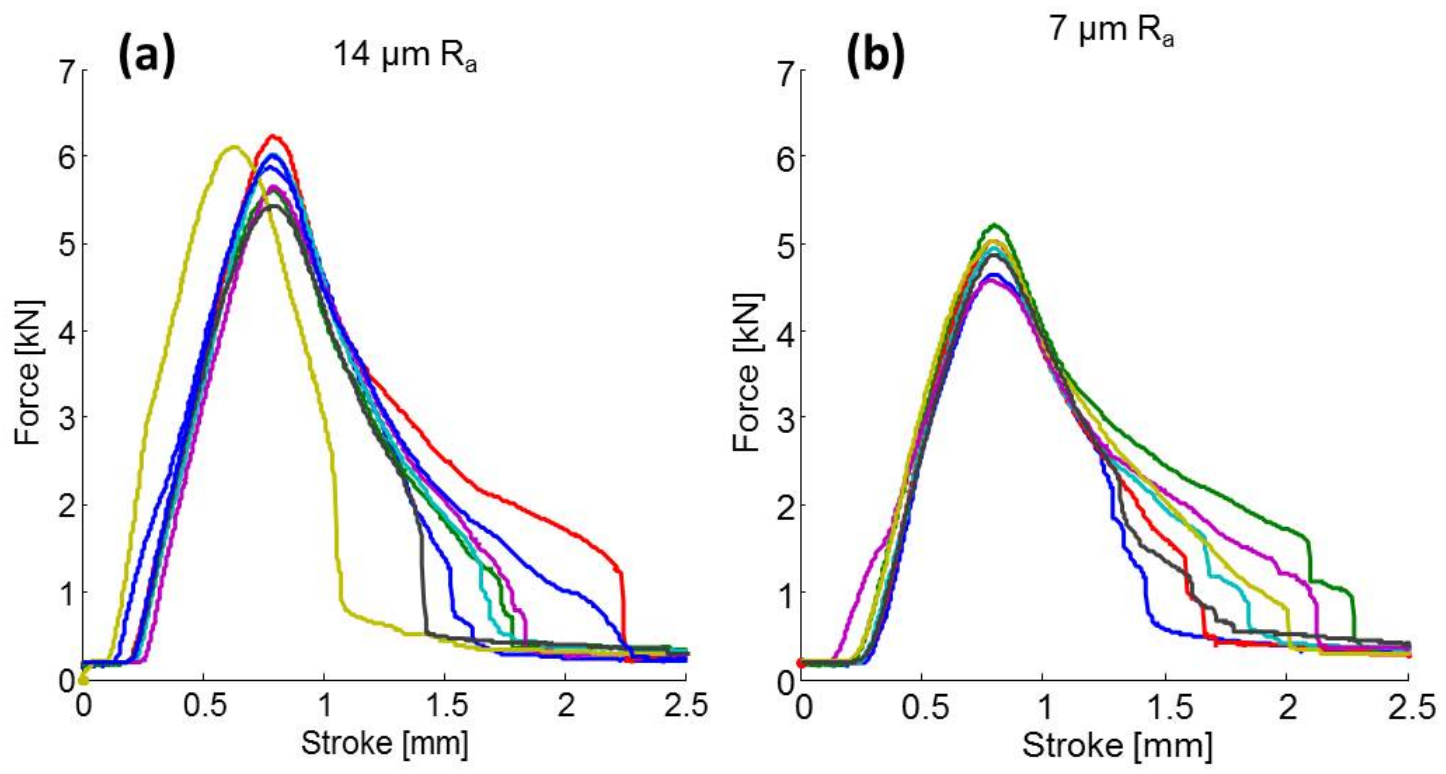

Figure 5: Push-pin results: (a) $14 \mu \mathrm{m} \mathrm{R} \mathrm{R}_{a}$; (b) $7 \mu \mathrm{m} \mathrm{R}_{a} .14 \mu \mathrm{m} \mathrm{R}_{a}$ shows consistently higher peak force.

Table 5: Results of push-pin testing with varying roughness sonotrodes.

\begin{tabular}{|c|c|c|c|}
\hline \multicolumn{2}{|c|}{$7 \mu \mathrm{m}$ Roughness } & \multicolumn{2}{c|}{$14 \mu \mathrm{m}$ Roughness } \\
\hline Max Force $(\mathrm{kN})$ & Energy $(\mathrm{kN}-\mathrm{mm})$ & Max Force $(\mathrm{kN})$ & Energy $(\mathrm{kN}-\mathrm{mm})$ \\
\hline 4.66 & 6.33 & 5.88 & 7.34 \\
\hline 5.21 & 8.16 & 5.6 & 7.46 \\
\hline 5.04 & 6.76 & 6.23 & 9.07 \\
\hline 4.95 & 7.13 & 6.02 & 7.79 \\
\hline 4.58 & 7.95 & 5.66 & 7.79 \\
\hline 5.02 & 7.64 & 6.11 & 7.27 \\
\hline 4.88 & 7.09 & 5.44 & 7.39 \\
\hline- & - & 6.01 & 8.51 \\
\hline
\end{tabular}

Cross sections of builds from each of the textured samples are shown in Figure 6. The baseplate and first welded layer are present in each of the sections. Since the baseplate is Al 6061-T6, it has a slightly different appearance than the welded layers. As is seen, each of the 
Table 6: Summary of unpooled t-test p-values, indicating the probability that the effect from the two surface roughnesses is equivalent (null hypothesis).

\begin{tabular}{|c|c|}
\hline & $\mathrm{p}$-Value \\
\hline Max Force $(\mathrm{kN})$ & $<0.0001$ \\
\hline Energy $(\mathrm{kN}-\mathrm{mm})$ & 0.1378 \\
\hline
\end{tabular}

samples appears voidless. The difference in roughness at the baseplate layer is apparent in each of the samples with more roughness shown in the $14 \mu \mathrm{m}$ sample.

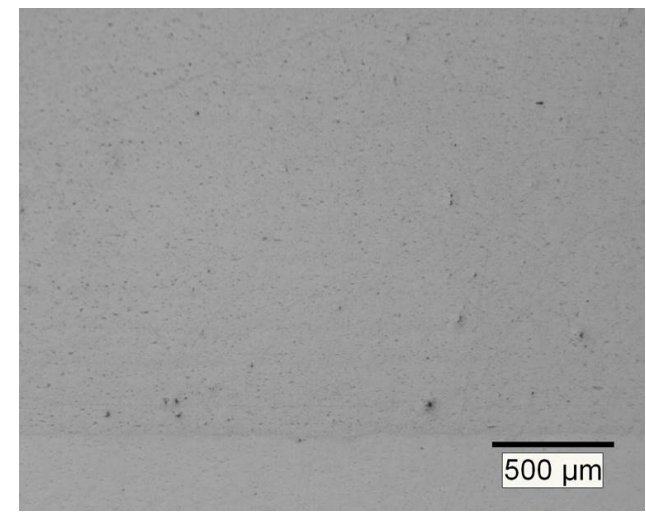

(a) $7 \mu \mathrm{m}$

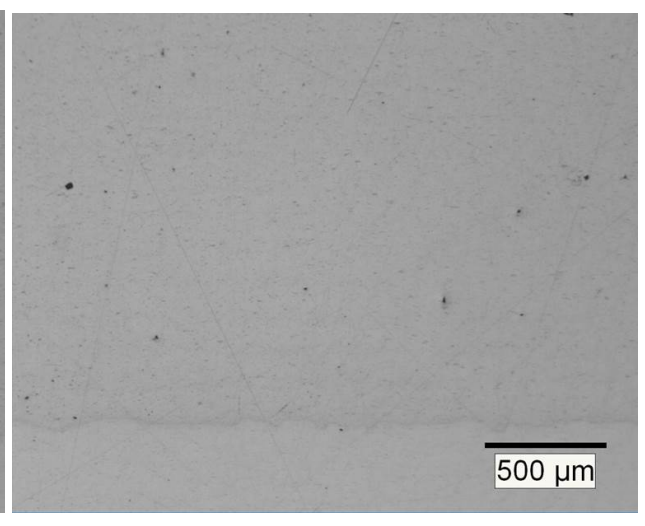

(b) $14 \mu \mathrm{m}$

Figure 6: Cross section of UAM builds with $7 \mu \mathrm{m}$ and $14 \mu \mathrm{m}$ roughnesses.

Based on the push-pin testing and microscopy, enhanced bond quality can be achieved using a $14 \mu \mathrm{m} R_{a}$ roughness sonotrode compared to a $7 \mu \mathrm{m} R_{a}$ sonotrode. Li and Soar (2009) also noted that rougher sonotrode surfaces produced better bonds using the same UAM processing settings [21]. However, they also reported that rougher surfaces increase the void concentration at weld interfaces. As seen in Figure 6, the larger weld amplitudes and down force of $9 \mathrm{~kW}$ UAM remedies earlier reporting of this interface void presence. However, it is suspected that interface voids can still form during UAM if sonotrodes rougher than $14 \mu \mathrm{m} R_{a}$ are used or if lower weld amplitudes and normal forces are utilized. Consequently, selecting an optimal surface roughness for a given material or UAM welding application may be needed as discussed originally by Friel et al. (2010) [22].

The improved bond quality associated with rougher surfaces is likely to originate in the con- 
solidation at the interface, similar to the effect seen in roughened vs. smooth surfaces. Due to the asperities being larger, more plastic deformation may occur, which would enhance the bonding mechanisms of oxide fracture, dispersal, and increase the driving force for dynamic recrystallization. Push-pin testing showed strong statistical significance with peak force compared to push-out energy. It is suspected that peak force during push-pin testing is enhanced from the $14 \mu \mathrm{m}$ sonotrode roughness because it increases the resistance to initial crack formation, while push-out energy is unaffected because it is a measure of the resistance to crack propagation. Further work using mechanical testing and microscopy is required to understand these failure energy differences.

Reporting the magnitude of surface roughness is only part of the surface profile. The statistical distribution of the surface profile is also important. However, this statistical distribution was not extensively measured for the UAM sonotrodes in this study. Further work may be required to understand the influence of asperity distribution on UAM build properties. Also, it may be required to include asperity magnitude and distribution information to more rigorously standardized UAM horn performance. Current work regarding the effect of contact mechanics, shows that plastic deformation occurs through the height of the asperities in the aluminum [29]. This indicates that the height of the asperities increases the zone of plastic deformation, which would in turn increase recrystallization with the bond region.

\section{Post-Process Heat Treatment}

\subsection{Experimental}

To test the effects of heat treatments on out-of-plane UAM tensile strength, a 0.8 in. (20.32 $\mathrm{mm})$ tall UAM block was fabricated using Al 6061-H18 foils 1 in. (25.4 mm) wide and 0.006 in. $(0.1524 \mathrm{~mm})$ thick. This build was constructed using the weld parameters in Table 1 with a $7 \mu \mathrm{m}$ horn, and did not use tape to tape overlaps or flattening passes. From this block, 9 cylindrical samples were sectioned using wire electrical discharge machining. These samples were sectioned avoiding any seam locations. Three samples were annealed, three were treated to a T6 condition, and three samples were tested as-built. Selection of the heat treated samples was randomized along the length of the weld. The specific heat treatment temperatures and settings as described by ASM standards are summarized below. 
For annealing (O): Heat to $413{ }^{\circ} \mathrm{C}$ for 2.5 hours, cool at $1{ }^{\circ} \mathrm{C} / \mathrm{min}$ until $280{ }^{\circ} \mathrm{C}$, then air cool [30]. For T6: Heat to $530{ }^{\circ} \mathrm{C}$ for $1 \mathrm{hr}$ to solutionize, quench in water, heat to $160{ }^{\circ} \mathrm{C}$ for 18 hours [30]. H18: indicates an as-built condition.

Following heat treatment, samples were machined via CNC lathe to final dimensions for tensile testing. The dimensions for the specimens are based on ASTM standards [26]. Machined specimens were then tested in tension using a $22 \mathrm{kip}(98.7 \mathrm{kN})$ Interlaken 3300 test frame with displacement rate of $0.05 \mathrm{in} / \mathrm{min}(1.27 \mathrm{~mm} / \mathrm{min})$.

\subsection{Results and Discussion}

Out-of-plane ultimate tensile test results are summarized in Table 7. Three tests were performed for each set, though one T6 sample was damaged during test setup. In Table 8, fractional comparisons to initial foil stock in each of the H18, T6, and $\mathrm{O}$ conditions are presented. $\mathrm{H} 18$ comparisons used as-received stock tested in tension with no heat treating, while foils for the annealed and T6 references were processed using the same heat treatment as the samples from the UAM block build and tested. Of note, the elongation values provided are not exact as they represent deflection of the entire load frame measured by the linear variable differential transformer (LVDT). However, the given displacement values can provide useful comparative evaluations. Use of an extensometer was not possible due to the small sample size of the specimens.

Table 7: Ultimate tensile strength results for heat treated UAM samples.

\begin{tabular}{|c|c|c|}
\hline Group & UTS (MPa) & \% Elongation \\
\hline H18 & 141.7 & 1.65 \\
\hline H18 & 123.8 & 1.1 \\
\hline H18 & 141.2 & 1.35 \\
\hline T6 & 296.8 & 14.98 \\
\hline T6 & 303.7 & 11.26 \\
\hline O & 129.2 & 15.27 \\
\hline O & 97.8 & 6.2 \\
\hline O & 124.4 & 19.7 \\
\hline
\end{tabular}

Failed samples and failure surfaces of an as-built and annealed sample are shown in Figure 7. As is shown, there is significantly more ductility observed in the annealed sam- 
Table 8: Comparison of UAM samples with solid material references.

\begin{tabular}{|c|c|c|c|c|c|c|}
\hline Group & $\begin{array}{c}\text { Avg. UTS } \\
(\mathrm{MPa})\end{array}$ & $\begin{array}{c}\text { Avg. Elo. } \\
(\%)\end{array}$ & $\begin{array}{c}\text { Ref. UTS } \\
(\mathrm{MPa})\end{array}$ & $\begin{array}{c}\text { Ref. Elo. } \\
(\%)\end{array}$ & $\begin{array}{c}\text { UTS (compare) } \\
(\%)\end{array}$ & $\begin{array}{c}\text { Elo. (compare) } \\
(\%)\end{array}$ \\
\hline H18 & 135.6 & 1.4 & 266.1 & 3.1 & 51 & 45 \\
\hline T6 & 300.3 & 13.1 & 337.3 & 12.5 & 89 & 105 \\
\hline O & 117.1 & 13.7 & 121.1 & 18.6 & 97 & 74 \\
\hline
\end{tabular}

ple (b) as compared to the as-built (a) sample. The failure in the tensile samples shows a brittle failure mode in the as-built sample, and a ductile failure in the annealed sample asevidenced by the diagonal failure surface. In the as-built sample, the majority of the sample failure is by delamination or brittle failure, with some limited ductility shown on the left side of the image. By contrast, the annealed sample shows ductile failure throughout, with failure through multiple layers as shown by the arrows in the image. This type of ductile failure was observed in both the annealed and T6 treated sample sets. These results correlate well with the tensile results for elongation, with as-built samples failing at significantly lower ductility (3\%) compared to the $\mathrm{T} 6(\mathbf{1 2 . 5 \% )}$ ) and annealed (18.6\%) sets.

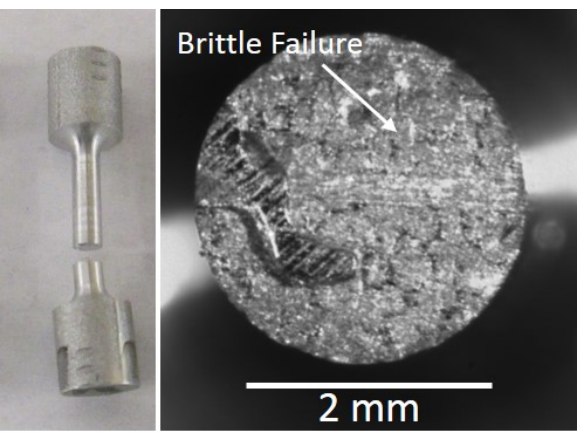

(a)

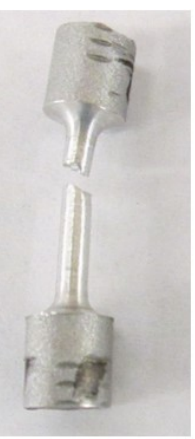

(b)

Figure 7: (a) Failed tensile sample and failure surface of typical as-built sample failure with indication of large area of brittle failure (b) Failed tensile sample and failure surface of typical heat treated sample failure with arrows indicating ductile failure through multiple layers.

The following comments can be made for each of the heat treatment groups:

- H18: For the as-welded group, there is a $50 \%$ decrease in strength and a $62 \%$ decrease 
in elongation when compared to the initial Al 6061-H18 foil stock. The decrease in elongation is somewhat expected due to the cold working effect imparted during the UAM process. The decrease in strength, while substantial, is a significant increase over samples made via $1 \mathrm{~kW}$ UAM by Hopkins et al. (2012) which exhibited strengths on the order of $15 \%$ of the parent material [13]. Implementing concepts of periodic flattening passes, rougher sonotrodes, and using recently developed power control concepts by Hehr et al. [17] could further increase this as-welded UAM build strength.

- T6: The T6 group shows very promising results when compared to homogeneous $\mathrm{Al} 6061$. The T6 condition is the most common form of $\mathrm{Al} 6061$, so the ability to produce welded components with the same temper and mechanical properties is an important benchmark for UAM. Strength of the UAM composites is $89 \%$ of the heat treated foil, and the elongation is roughly $105 \%$. While the strength does not exactly match solid material, these metrics show that near T6 properties of UAM composites can be achieved through post process heat treatments.

- Annealed (O): This group, similar to the T6 group, shows promising results when compared to the annealed foils. The strength is $96 \%$ of the annealed foil and the elongation is $74 \%$, with a potential outlier failing at $6.2 \%$ elongation accounting for the decrease in elongation.

Optical microscopy images of a T6 heat treated and as-welded UAM sample are shown in Figure 8. The microstructure in each case shows indications of precipitates, typical in $\mathrm{Al}$ 6061, with the dark colored precipitates $\mathrm{Mg}_{2} \mathrm{Si}$ and the lighter precipitates AlFeSi intermetallics. These precipitates are the primary strengthening mechanism in $\mathrm{Al} \mathrm{6061.} \mathrm{As} \mathrm{can} \mathrm{be} \mathrm{seen,} \mathrm{significantly}$ more precipitates are present in the heat treated sample, compared to the as-welded sample. The increased presence of these precipitates is expected to increase the strength of the samples significantly, consistent with mechanisms present in solid material shown by Songmene et al. (2012) [31]. 


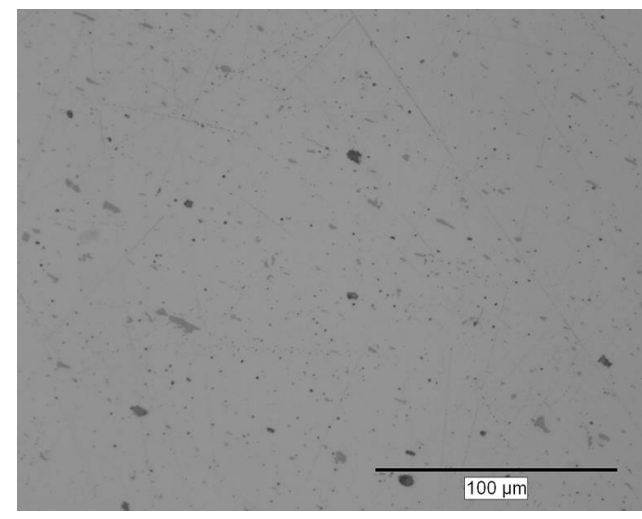

(a)

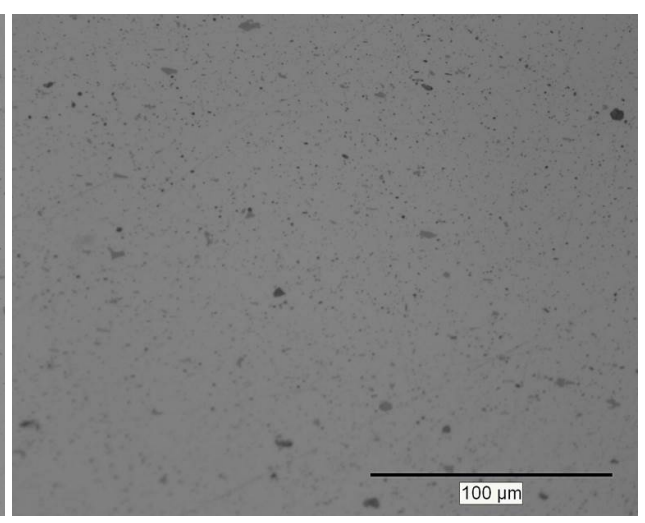

(b)

Figure 8: Microstructure showing precipitate density of (a) T6 heat treated and (b) as-built sample.

Overall these results indicate that the mechanical properties of UAM structures can be enhanced considerably when a post process heat treatment is applied. These heat treatment results coincide well with the microscopy work by Sojiphan et al. (2012) in Al 3003 [24]. In particular, Sojiphan et al. (2012) observed that the recrystallized grain structure at weld interfaces in optimized aluminum UAM builds was very stable after heat treating. This stable microstructure results in less defects and defect nucleation sites, which, in turn improves mechanical properties. It was also observed that significant recrystallization and grain growth occurred in the bulk weld foil after heat treating. Heat treating also enhances precipitate distribution and concentration in Al 6061 (see Figure 8). Consequently, strength improvements are suspected to be a combination of improved precipitate density and microstructure stability.

\section{Concluding Remarks}

Studies were conducted investigating improvements to the UAM process. An optimal stacking and overlap sequence for builds larger than the tape width is proposed which uses random stacking and a tape to tape overlap of at least $0.0025 \mathrm{in}$. $(0.0635 \mathrm{~mm})$. Investigations of the effect of surface roughness on build strength indicate that imparting a roughness on the order of the sonotrode roughness can increase mechanical strength compared to an as-machined (smooth) surface roughness. Use of $14 \mu \mathrm{m} \mathrm{R}_{a}$ roughness sonotrodes show an improvement in mechanical properties compared to welds made using a $7 \mu \mathrm{m} \mathrm{R}_{a}$ sonotrode. Heat treatments performed after 
joining were shown to provide significant increases in mechanical strength with tensile strengths for the T6 condition approaching 90\% of solid material. These improvements are suggested to maximize the strength of future builds, where applicable.

Recommendations for Al 6061- H18 UAM block builds:

- Tape overlap $>0.0025$ in. $(0.0635 \mathrm{~mm})$

- Random stacking sequence with maximum overlap of $0.3 \mathrm{in}$. (7.62 mm)

- Conduct surface roughening where applicable

- Utilize $14 \mu \mathrm{m} \mathrm{R}_{a}$ roughness sonotrode

- For Al 6061 structures, heat treatments to the T6 condition provide the highest tensile strength

\section{Acknowledgements}

The authors would like to thank David Tung of the Welding Engineering department for his assistance with push-pin testing. Funding for P.W. was provided by the Fellowship Program of the NSF I/UCRC Center on Smart Vehicle Concepts, www.SmartVehicleCenter.org. Support for A.H. comes from a National Science Foundation Graduate Fellowship under Grant No. 1102690. Any opinions, findings, and conclusions or recommendations expressed in this material are those of the authors and do not necessarily reflect the views of the National Science Foundation.

\section{References}

[1] D. White, Ultrasonic consolidation of aluminum tooling, Advanced materials \& processes 161 (1) (2003) 64-65.

[2] K. Graff, New Developments in Advanced Welding, Woodhead Publishing Limited, 2005.

[3] M. Norfolk, H. Johnson, Solid-state additive manufacturing for heat exchangers, JOM 67 (3) (2015) $655-659$.

[4] M. Sriraman, S. Babu, M. Short, Bonding characteristics during very high power ultrasonic additive manufacturing of copper, Scripta Materialia 62 (2010) 560-563.

[5] C. Kong, R. Soar, P. Dickens, Ultrasonic consolidation for embedding SMA fibres within aluminium matrices, Composite Structures 66 (2004) 421-427.

[6] R. Hahnlen, M. Dapino, NiTi-Al interface strength in ultrasonic additive manufacturing composites, Composites: Part B 59 (2014) 101-108.

[7] C. Kong, R. Soar, Fabrication of metal-matrix composites and adaptive composites using ultrasonic consolidation process, Materials Science \& Engineering A 412 (1-2) (2005) 12-18. 
[8] E. Siggard, Investigative research into the structural embedding of electrical and mechanical systems using ultrasonic consolidation, Master's thesis, Utah State University, Logan, UT (2007).

[9] C. Hopkins, S. Fernandez, M. Dapino, Statistical Characterization of Ultrasonic Additive Manufacturing Ti/Al Composites, Journal of Engineering Materials and Technology 132 (2010) 041006-1-041006-9.

[10] A. Truog, Bond Improvement of Al/Cu Joints Created by Very High Power Ultrasonic Additive Manufacturing, Master's thesis, The Ohio State University, Columbus, OH (2012).

[11] J. Obielodan, A. Ceylan, L. Murr, B. Stucker, Multi-material bonding in ultrasonic consolidation, Rapid Prototyping Journal 16 (3) (2010) 180-188.

[12] P. Wolcott, A. Hehr, M. Dapino, Optimized welding parameters for Al 6061 ultrasonic additive manufactured structures, Journal of Materials Research 29 (27) (2014) 2055-2065.

[13] C. Hopkins, P. Wolcott, M. Dapino, A. Truog, S. Babu, S. Fernandez, Optimizing ultrasonic additive manufactured Al 3003 properties with statistical modeling, Journal of Engineering Materials and Technology 134 (2012) 0110041-011004-10.

[14] K. Graff, M. Short, M. Norfolk, Very High Power Ultrasonic Additive Manufacturing (VHP UAM), in: Solid Freeform Fabrication Symposium, Austin, TX, 2011.

[15] H. Fujii, M. Sriraman, S. Babu, Quantitative evaluation of bulk and interface microstructures in Al-3003 alloy builds made by very high power ultrasonic additive manufacturing, Metallurgical and Materials Transactions A $42 \mathrm{~A}$ (2011) 4045-4055.

[16] C. Robinson, C. Zhang, G. Janaki-Ram, E. Siggard, B. Stucker, L. Li, Maximum height to width ratio of freestanding structures built by ultrasonic consolidation, in: Solid Freeform Fabrication Symposium, Austin, TX, 2006.

[17] A. Hehr, P. J. Wolcott, M. J. Dapino, Effect of Weld Power and Build Compliance on Ultrasonic Consolidation, Rapid Prototyping Journal In Press.

[18] J. Gibert, E. Austin, G. Fadel, Effect of height to width ratio on the dynamics of ultrasonic consolidation, Rapid Prototyping Journal 16 (4).

[19] J. Obielodan, G. Janaki-Ram, B. Stucker, D. Taggart, Minimizing defects between adjacent foils in ultrasonically consolidated parts, Journal of Engineering Materials and Technology 132 (2010) 011006-1-011006-8.

[20] Fabrisonic-LLC, "http://www.fabrisonic.com".

[21] D. Li, R. Soar, Influence of sonotrode texture on the performance of an ultrasonic consolidation machine and the interfacial bond strength, Journal of Materials Processing Technology 209 (2009) 1627-1634.

[22] R. Friel, K. Johnson, P. Dickens, R. Harris, The effect of interface topography for ultrasonic consolidation of aluminum, Materials Science and Engineering A 527 (2010) 4474-4483.

[23] G. Janaki Ram, Y. Yang, J. George, C. Robinson, B. Stucker, Improving linear weld density in ultrasonically consolidated parts, in: Solid Freeform Fabrication Symposium, Austin, TX, 2006.

[24] K. Sojiphan, S. Babu, X. Yu, S. Vogel, Quantitative evaluation of crystallographic texture in aluminum alloy builds fabricated by very high power ultrasonic additive manufacturing, in: Solid Freeform Fabrication Symposium, Austin, TX, 2012.

[25] C. Zhang, A thermomechanical analysis of an ultrasonic bonding mechanism, Ph.D. thesis, Utah State University, Logan, UT (2011). 
[26] ASTM-International, E8/E8M: Standard Test Methods for Tension Testing of Metallic Materials (2009).

[27] C. Zhang, A. Deceuster, L. Li, A Method for Bond Strength Evaluation for Laminated Structures with Application to Ultrasonic Consolidation, J. of Materials Engineering and Performance 18 (8) (2009) 1124-1132.

[28] R. Dehoff, S. Babu, Characterization of interfacial microstructures in 3003 aluminum alloy blocks fabricated by ultrasonic additive manufacturing, Acta Materialia 58 (2010) 4305-4315.

[29] P. Wolcott, Ultrasonic additive manufacturing: Weld optimization for aluminum 6061, development of scarf joints for aluminum sheet metal, and joining of high strength metals, Ph.D. thesis, The Ohio State University, Columbus, $\mathrm{OH}(2015)$.

[30] ASM-International, Heat Treating - Heat Treating of Aluminum Alloys, Vol. 4, ASM International, 1991.

[31] V. Songmene, J. Kouam, I. Zaghbani, N. Parson, A. Maltais, Global Machinability of Al-Mg-Si Extrusions - New Trends in Fabrication and Applications, InTech, 2012. 